\title{
Validity of the Korean Developmental Screening Test for very-low-birth-weight infants
}

\author{
Chae Young Kim, MD, Euiseok Jung, MD, Byong Sop Lee, MD, Ki-Soo Kim, MD, Ellen Ai-Rhan Kim, MD \\ Division of Neonatology, Department of Pediatrics, Asan Medical Center Children's Hospital, University of Ulsan College of Medicine, Seoul, Korea
}

Purpose: The importance of the neurodevelopmental outcomes of very-low-birth-weight (VLBW) infants has been emphasized as their mortality rate has markedly improved. This study aimed to assess the validity of the Korean Developmental Screening Test (K-DST), a developmental screening tool approved by the Korean Society of Pediatrics, for the timely diagnosis of neurodevelopmental delay in VLBW infants.

Methods: Subjects included VLBW infants enrolled in the Korean Neonatal Network database between January 2012 and December 2014. The collected data were analyzed for sensitivity, specificity, positive predictive value, and negative predictive value (NPV) in the K-DST compared to those in the Bayley Scales of Infant Development-II for VLBW infants.

Results: A total of 173 patients were enrolled. Their mean gestational age and mean birth weight were $27.5 \pm 2.8$ weeks and $980.5 \pm 272.1 \mathrm{~g}$, respectively. The frequency of failed psychomotor developmental index (PDI) $<85$ was similar to that in at least one domain of K-DST $<1$ standard deviation. Failure in more than one K-DST domain compared with a mental developmental index (MDI) $<85$ showed a sensitivity and NPV of $73.2 \%$ and $75.0 \%$, respectively. Failure in more than one K-DST domain compared with PDI $<85$ showed a sensitivity and NPV of $60.3 \%$ and $71.6 \%$, respectively. Each K-DST domain had a stronger correlation with predicting a failing $\mathrm{MDI}<85$ than a failing $\mathrm{PDI}<85(P<0.05)$. Conclusion: K-DST could be a useful screening tool for predicting mental developmental delay in VLBW infants and referring them for neurodevelopmental assessments.

Key words: Very low birth weight, Validity, Korean Developmental Screening Test

\section{Introduction}

Preterm birth is an important cause of perinatal mortality and long-term morbidities. ${ }^{1-3)}$ The survival rate of preterm infants has steadily increased because of improved prenatal and perinatal medicine. In a previous study, preterm birth rate was approximately $11.5 \%$ in the United States (US) and the survival rate among infants born 23-24 weeks in developed countries was approximately 50\%. ${ }^{1)}$ In Korea, the survival rates of very-low- birth-weight (VLBW) infants have also increased; they were 65.8\% in the early 1990 s and 89.7\% in 2009. ${ }^{2}$ The importance of neurodevelopmental outcomes of VLBW infants is emphasized as their mortality rate has dramatically improved. The risk of poor neurodevelopmental outcomes remains high in children who are born preterm. ${ }^{1-3)}$ Approximately 25\% of extremely preterm infants born in the 1990s had critical disabilities such as impaired mental development, cerebral palsy, blindness, and deafness at preschool age. ${ }^{3,4)}$ An early recognition of abnormal neurodevelopment for preterm infants is able to overcome neurodevelopmental delay through specific intervention programs and minimize risks of irreversible dysfunction, eventually improving the quality of life. Thus, neurodevelopmental assessment using appropriate tools is
Corresponding author: Ellen Ai-Rhan Kim, MD Division of Neonatology, Department of Pediatrics, Asan Medical Center Children's Hospital, University of Ulsan College of Medicine, 88, Olympic-ro 43gil, Songpa-gu, Seoul 05505, Korea

Tel: $+82-2-3010-3352$

Fax: +82-2-3010-7302

E-mail: arkim@amc.seoul.kr

https://orcid.org/0000-0002-9859-3021

Received: 24 December, 2018

Revised: 1 March, 2019

Accepted: 19 March, 2019

\section{Copyright (® 2019 by The Korean Pediatric Society}

This is an open-access article distributed under the terms of the Creative Commons Attribution NonCommercial License (http://creativecommons.org/ licenses/by-nc/4.0/) which permits unrestricted noncommercial use, distribution, and reproduction in any medium, provided the original work is properly cited. 
important. $^{5)}$

The Bayley Scales of Infant and Toddler Development-II (BSIDII) is the most widely used measure to assess neurodevelopmental outcome of preterm (gestational age $\leq 32$ weeks) or very low birth weight (VLBW, birth weight $\leq 1,500 \mathrm{~g}$ ) infants aged 1 month to 3 years 6 months. ${ }^{6,7)}$ The BSID-II is composed of 2 types of developmental scores: the Mental Developmental Index (MDI), which evaluates cognitive and language development, and the Psychomotor Developmental Index (PDI), which evaluates motor skills. However, the disadvantages of BSID-II include its long test duration, need for a highly skilled person to interpret results, and low costeffectiveness. ${ }^{8,9}$ Moreover, whether using BSID-II in Korea is appropriate remains uncertain because its original norms are based on the US population.

In Korea, the Ages and Stages Questionnaires (ASQ) developed in the US has been revised into a Korean version (K-ASQ), which has been standardized for assessment of Korean pediatric development since the year 2000. ${ }^{10)}$ Because the K-ASQ is a domestic version of the ASQ, which was developed in the US as a parent-type infant monitoring system, it is a relatively reliable test for a test that was made for foreign infants who grow up in a culturally different environment. Therefore, it has some deficiencies in social and self-help areas for Korean infants and toddlers, and there are limitations in that it cannot be used on the Web due to the copyright. Therefore, these limitations have increased the need for appropriate testing tools for infants and young children in Korea. The Korean-Developmental Screening Test for infants and children (K-DST), a developmental screening tool acknowledged by the Korean Society of Pediatrics for infant and child health screening, has been available for screening neurodevelopmental delay in Korean children since 2014. ${ }^{11)}$ This test verifies whether Korean infants have standard development in the 6 domains of gross motor, fine motor, cognition, language, sociality, and self-help. ${ }^{11}$ However, only nonpremature infants and children in local clinics due to development problems were enrolled in this study. There are still not enough studies on the usefulness of the K-DST for the assessing the development of VLBW infants. Therefore, the objective of this study was to evaluate the validity of the K-DST for timely diagnosis of neurodevelopmental delay in VLBW infants compared to the BSID-II.

\section{Materials and methods}

\section{Study design}

We retrospectively reviewed the medical records of infants who were enrolled in the Korean Neonatal Network (KNN), a nationwide systemic database, from January 2012 to December 2014. These infants were from 55 neonatal intensive care units (NICUs) of KNNparticipating hospitals, were born with birth weights $<1,500 \mathrm{~g}$ and survived, and had available BSID-II and K-DST scores at corrected age 18-24 months old. Primary caretakers were asked to fill out the K-DST at the time of BSID-II examination from January 2014 to May 2017. For both tests, the tests performed were for the age that corresponded most closely to the infant's corrected age. Exclusion criteria included major congenital anomalies or chromosome abnormalities, and were not having been followed up on until 3 years of age.

Demographic characteristics of subjects included gestational age, birth weight, sex, APGAR scores (1 and 5 minutes), respiratory distress syndrome (RDS), patent ductus arteriosus (PDA), bronchopulmonary dysplasia (BPD, severity defined by criteria of the National Institute of Child Health and Human Development), ${ }^{12)}$ intraventricular hemorrhage (IVH, grade $\geq 2$, defined by Papile), ${ }^{13)}$ periventricular leukomalacia, necrotizing enterocolitis (NEC, stage $\geq 2$, defined by Bell), ${ }^{14)}$ late-onset sepsis defined as a case of positive blood culture after postnatal 7 days, ${ }^{15)}$ retinopathy of prematurity (ROP, stage $\geq 2$, defined by the International Classification of Retinopathy of Prematurity), ${ }^{16)}$ congenital hypothyroidism, hearing loss (including mild hearing loss of 20-40 dB), cerebral palsy (diagnosed by a board-certified doctor of pediatric rehabilitation medicine), and hospital days.

Developmental delay for VLBW infants was defined when MDI or PDI scores were less than 85 on BSID-II. They were patients who needed follow-up or further evaluation. To evaluate the ability of the K-DST to identify VLBW infants with developmental delay, critical cutoff scores for 6 domains-gross motor, fine motor, cognition, language, sociality, and self-help-were set at 1 standard deviation (SD) under the mean value. They were also patients who needed follow-up or further evaluation based on the K-DST. The validity of the K-DST was then determined by calculating its sensitivity, specificity, positive predictive value (PPV), and negative predictive value (NPV) compared to MDI or PDI $<85$ on BSID-II.

Although it could not be precisely distinguished, MDI was compared with cognition, language, the K-DST, and PDI was compared with gross motor, fine motor, and self-help.

\section{Statistical analysis}

Statistical analysis was performed using IBM SPSS Statistics ver. 21.0 (IBM Co., Armonk, NY, USA). Results are presented as medians or means \pm SD for quantitative variables and as percentages for nonquantitative variables. Correlation between BSID-II and K-DST was performed using a chi-square test and Spearman rank-order correlation. Differences were considered significant at $P<0.05$.

\section{Ethical statement}

The data registry was approved by the Institutional Review Board as each hospital was a participant in the KNN (2013-0370). Informed consent was obtained from all patients through their enrollment in NICUs participating in the KNN. 


\section{Results}

A total of 196 VLBW infants were enrolled in this study. Of these, 173 VLBW infants (88.3\%) were able to be followed up with until a corrected age of 18-24 months. Mean gestational age and birth weight of these infants were $27.5 \pm 2.8$ weeks and $980.5 \pm 272.1 \mathrm{~g}$, respectively (Table 1). Regarding neonatal morbidity, the incidence of RDS, significant PDA, moderate to severe BPD, IVH $\geq$ grade 2 , NEC $\geq$ stage 2, and ROP $\geq$ stage 2 was 80.9\%, 32.3\%, 24.9\%, 36.4\%, $4.0 \%$, and $18.5 \%$, respectively. The incidence of hearing loss, visual loss, and cerebral palsy was $0 \%, 0 \%$, and $0.5 \%$, respectively. The mean duration of hospital stay of the infants was $79.4 \pm 39.5$ days (Table 1).

The mean age at which both BSID-II and K-DST scores were obtained was at corrected 20.9 \pm 2.3 months (range, 18-24 months).

Table 1. Demographic characteristics of enrolled subjects $(n=173)$

\begin{tabular}{lc}
\hline Variable & Value \\
\hline Gestational age (wk) & $27.5 \pm 2.8$ \\
Birth weight (g) & $980.5 \pm 272.1$ \\
Male sex & $89(51.4)$ \\
APGAR score at 1 min & $4(2-7)$ \\
APAGR score at 5 min & $6(5-9)$ \\
Respiratory distress syndrome & $140(80.9)$ \\
Significant patent ductus arteriosus & $56(32.3)$ \\
Moderate to severe bronchopulmonary dysplasia & $43(24.9)$ \\
Intraventricular hemorrhage (grade $\geq 2)$ & $63(36.4)$ \\
Periventricular leukomalacia & $7(4.0)$ \\
Necrotizing enterocolitis (stage $\geq 2)$ & $7(4.0)$ \\
Late-onset sepsis & $40(23.1)$ \\
Retinopathy of prematurity (stage $\geq 2)$ & $32(18.5)$ \\
Hearing loss & $0(0)$ \\
Visual loss & $0(0)$ \\
Cerebral palsy & $1(0.5)$ \\
Hospital stay (day) & $79.4 \pm 39.5$ \\
\hline Values are presented as mean \pm standard deviation, mean (interquartile range), \\
or number (\%).
\end{tabular}

The proportion of developmental delay on the BSID-II was 40.5\% for MDI and 30.6\% for PDI (Table 2). The proportion of developmental delay for the 6 domains of the K-DST was $28.7 \%$ on average. Proportions of developmental delay in gross motor, fine motor, cognition, language, sociality, and self-help on the K-DST were $29.6 \%$, 30.1\%, 30.1\%, 33.2\%, 25.5\%, and 23.9\%, respectively.

Table 3 shows the validity of each of the K-DST domains compared to $\mathrm{MDI}<85$. Sensitivity, specificity, PPV, and NPV of the six domains of the K-DST based on the BSID-II were in the range of $0.256-0.5,0.829-0.919,0.538-0.804$, and 0.604-0.711, respectively. Sensitivity and NPV for more than one domain failed on the $\mathrm{K}-\mathrm{DST}$ relative to $\mathrm{MDI}<85$ were 0.732 and 0.750 , respectively.

Furthermore, Table 3 shows the validity of each of the K-DST domains compared to $\mathrm{PDI}<85$. Sensitivity, specificity, PPV, and NPV of the $6 \mathrm{~K}-\mathrm{DST}$ domains based on BSID-II were in the range of 0.175-0.349, 0.762-0.854, 0.314-0.431, and 0.671-0.711, respectively. Sensitivity and NPV for more than one domain failed on the K-DST relative to PDI <85 were 0.603 and 0.716 , respectively.

We assessed the correlation between K-DST and BSID-II using Spearman rank-order correlation (Table 4). The Spearman correlation coefficients of all 6 K-DST domains were between 0.170 and 0.615 , showing a significant correlation with the four domains (fine motor, cognition, language, and sociality) of the MDI and K-DST. The MDI showed a more significant positive correlation with the K-DST than did the PDI, with higher Spearman's correlation coefficients of MDI than PDI. Language showed a stronger correlation ( $r=0.526$ ) with the MDI than the other domains did. However, this study did not show a significant correlation between the PDI and K-DST.

\section{Discussion}

The objective of this study was to assess the usefulness of the K-DST for VLBW infants born from 2012 to 2014 at 55 NICUs enrolled in KNN. Because the period between 20 and 32 weeks after conception is a period for rapid brain growth and development, ${ }^{17)}$

Table 2. Proportion of very-low-birth-weight infants who failed Bayley Scales of Infant and Toddler Development-II (BSID-II) or Korean-Developmental Screening Test (K-DST)

\begin{tabular}{llcc}
\hline Test & \multicolumn{1}{c}{ Domain } & No. (\%) & Index, mean \pm SD \\
\hline BSID-II & Mental developmental index <85 & $70(40.5)$ & $69.2 \pm 11.0$ \\
& Psychomotor developmental index $<85$ & $53(30.6)$ & $73.3 \pm 9.9$ \\
K-DST (<-1SD) & Gross motor & $58(29.6)$ & $17.3 \pm 0.7$ \\
& Fine motor & $59(30.1)$ & $19.4 \pm 2.0$ \\
& Cognition & $59(30.1)$ & $11.4 \pm 3.1$ \\
& Language & $65(33.2)$ & $9.2 \pm 3.5$ \\
& Sociality & $50(25.5)$ & $11.7 \pm 3.3$ \\
& Self-help & $47(23.9)$ & $13.7 \pm 1.8$ \\
\hline
\end{tabular}

SD, standard deviation. 
Table 3. Validity of Korean-Developmental Screening Test (K-DST) in comparison to Mental Developmental Index (MDI) and Psychomotor Developmental Index (PDI) of Bayley Scales of Infant and Toddler Development-II

\begin{tabular}{|c|c|c|c|c|c|c|c|c|}
\hline \multirow{2}{*}{ K-DST (<-1SD) } & \multicolumn{4}{|c|}{$\mathrm{MDI}<85$} & \multicolumn{4}{|c|}{ PDI $<85$} \\
\hline & Sensitivity & Specificity & PPV & NPV & Sensitivity & Specificity & PPV & NPV \\
\hline Gross motor & 0.256 & 0.838 & 0.538 & 0.604 & 0.238 & 0.815 & 0.385 & 0.688 \\
\hline Fine motor & 0.354 & 0.829 & 0.604 & 0.634 & 0.270 & 0.762 & 0.354 & 0.683 \\
\hline Cognition & 0.427 & 0.874 & 0.714 & 0.674 & 0.333 & 0.785 & 0.429 & 0.708 \\
\hline Language & 0.500 & 0.910 & 0.804 & 0.711 & 0.349 & 0.777 & 0.431 & 0.711 \\
\hline Sociality & 0.317 & 0.919 & 0.743 & 0.646 & 0.175 & 0.815 & 0.314 & 0.671 \\
\hline Self-help & 0.280 & 0.919 & 0.719 & 0.634 & 0.206 & 0.854 & 0.406 & 0.689 \\
\hline$\geq 1$ Domain failed & 0.732 & 0.595 & 0.571 & 0.750 & 0.603 & 0.485 & 0.362 & 0.716 \\
\hline
\end{tabular}

PPV, positive predictive value; NPV, negative predictive value; SD, standard deviation.

Table 4. Correlation between Korean-Developmental Screening Test (KDST) domains and Bayley Scales of Infant and Toddler Development-II (BSID-II)

\begin{tabular}{lccccc}
\hline & \multicolumn{5}{c}{ BSID-II } \\
\cline { 2 - 3 } K-DST (<-1SD) & \multicolumn{2}{c}{ MDI } & \multicolumn{2}{c}{ PDI } \\
\cline { 2 - 3 } \cline { 5 - 6 } & $r^{\star}$ & \multicolumn{1}{c}{$P$ value } & & \multicolumn{1}{c}{$P$ value } \\
\hline Gross motor & 0.104 & 0.149 & & 0.133 & 0.065 \\
Fine motor & 0.200 & $\mathbf{0 . 0 0 5}$ & & 0.039 & 0.593 \\
Cognition & 0.498 & $<0.0001$ & & 0.105 & 0.147 \\
Language & 0.526 & $<0.0001$ & & 0.138 & 0.056 \\
Sociality & 0.384 & $<0.0001$ & & 0.039 & 0.594 \\
Self-help & 0.319 & 0.353 & & 0.104 & 0.150
\end{tabular}

SD, standard deviation; MDI, mental developmental index; PDI, psychomotor developmental index.

Boldface indicates a statistically significant difference with $P<0.05$.

*Spearman's rank correlation analysis.

comorbidity, infection, and malnutrition during neonatal care may lead to neurodevelopmental delay in preterm infants. Clinical consequences include serious neuromuscular problems such as cerebral palsy, visual and hearing loss, and learning difficulties and psychological, behavioral, and social difficulties in surviving preterm infants. ${ }^{18,19)}$ A recent study has demonstrated an association of prematurity with features of autism spectrum. ${ }^{20)}$ Therefore, regular follow-up assessments of children at risk of neurodevelopmental disabilities may enable appropriate screening of developmental delay, and timely medical, educational, and social policy can be provided. ${ }^{18-20)}$

While there is no standard tool for assessing developmental delay, the BSID and its revisions are the most widely used and welldesigned tools. ${ }^{21-23)}$ The second edition of the Bayley scales (BSIDII) has been used in previous studies to determine developmental disabilities in preterm children and perinatal factors associated with poor outcomes. ${ }^{24-26)}$ A meta-analysis has shown the positive predictive value of the BSID-II for the development of preterm and VLBW children ${ }^{27)}$ Neurodevelopmental outcomes of preterm children in Korea are also determined by screening instruments such as the Denver Developmental Screening Test-II (DDST-II) and the Ages and Stages Questionnaire in Korea (K-ASQ). ${ }^{10-11,28,29)}$ The DDST-II is widely used as the screening test for evelopmental delay in the four areas of social contact, fine motor skill, gross motor skill, and language. ${ }^{30)}$ The K-ASQ is a standardized and culturally modified version of the ASQ, which is a parent-completed questionnaire suitable for young children in the US population. ${ }^{30)}$ The DDSTII and K-ASQ may present some difficulties in reflecting special developments in Korean children. Recently studies reported that the detection rate of neurological impairment for the DDST-II was 50.7\% in neurological impairment of Korean infants, ${ }^{31)}$ and K-ASQ showed low validity for screening neurodevelopmentally delayed premature infants." ${ }^{9}$ To reinforce this point, the K-DST was developed with cultural appropriateness in mind by the Korean Society of Pediatrics in 2014. ${ }^{12)}$ The K-DST, which is suitable for Korean infants and children, generally evaluates standard development. ${ }^{12,32)}$ Compared to the DDST-II and K-ASQ, the K-DST compensates for unsuitable questions related to the sociality and self-help domains. ${ }^{29)}$ In Korea, almost all infants and children are now being assessed for their serial developmental status from 4 to 71 months of age using the K-DST at primary care clinics. ${ }^{29,33)}$ However, the usefulness of the K-DST to evaluate developmental delay in preterm children has not been studied. Having a useful developmental screening test for preterm infants is very important for the early diagnosis of developmental delays, as some cases could resolve to almost normal developmental outcomes when early intervention and rehabilitation programs are used. ${ }^{11,31)}$

In this study, the specificity of the individual K-DST domains compared to the BSID-II MDI and PDI was more than 70\% in VLBW infants. Previous studies have demonstrated that sensitivity and specificity levels of 70\% to 80\% and PPV and NPV levels of at least $80 \%$ are deemed acceptable for developmental screening tests. ${ }^{10,34,35)}$ However, the sensitivity of the K-DST compared to the BSID-II MDI and PDI was low (less than 70\%). Correlation analysis of the individual domains of the K-DST and BSID-II showed that four of the domains (fine motor, cognition, language, and sociality) on the K-DST were significantly associated with delayed BSIDII MDI scores, but not associated with delayed BSID-II PDI scores. 
This discrepancy may have arisen from cultural differences between Korea and the US. Each K-DST domain was more significantly associated with predicting failing the MDI than failing the PDI. In particular, the cognition, language, and sociality domains of the K-DST had stronger correlations with the MDI. However, when we evaluated the validity of the K-DST for 196 VLBW infants who survived and whose BSID-II and K-DST were available at a corrected age of 18-41 months, the Spearman correlation coefficients of all 6 K-DST domains showed a significant correlation between the MDI or PDI and the K-DST, although the results were not shown in this study.

There are several limitations in our study. First, the study population involved a small number of infants and toddlers with a wide range of corrected age. Second, although this study reviewed data from 55 NICUs in Korea, the testing ability of Bayley examiners has not been standardized, which may have caused inter-observer discrepancies. Third, The BSID-II assesses the cognitive component by a combined measure of cognition and language. ${ }^{19)}$ If the results were evaluated using the BSID-II, which was developed to separate MDI into cognitive delay and language delay and separate PDI into gross and fine, it would have increased sensitivity. Lastly, developmental questionnaires were performed by primary caretakers, usually parents, which may have caused recall bias as well. However, our study has strength in that it is the first study that demonstrates the validity of the K-DST among VLBW infants in Korea.

In conclusion, preliminary results of this study indicate that the K-DST could be useful as a screening tool for the accurate and timely diagnosis of mental developmental delay in VLBW infants. Other prospective clinical trials are required to find the validity of the K-DST compared to the Korean version of the BSID-II or the BSIDIII.

\section{Conflicts of interest}

No potential conflict of interest relevant to this article was reported.

\section{Acknowledgments}

The authors would like to thank the principal investigators and related researchers of the KNN-participating hospitals. This research was supported by a grant (2016-ER6307-02) from the Research of Korea Centers for Disease Control and Prevention.

\section{References}

1. Glass HC, Costarino AT, Stayer SA, Brett CM, Cladis F, Davis PJ.
Outcomes for extremely premature infants. Anesth Analg 2015;120: 1337-51.

2. Hahn WH, Chang JY, Chang YS, Shim KS, Bae CW. Recent trends in neonatal mortality in very low birth weight Korean infants: in comparison with Japan and the USA. J Korean Med Sci 2011;26:467-73.

3. Pierrat V, Marchand-Martin L, Arnaud C, Kaminski M, Resche-Rigon M, Lebeaux C, et al. Neurodevelopmental outcome at 2 years for preterm children born at 22 to 34 weeks' gestation in France in 2011: EPIPAGE-2 cohort study. BMJ 2017;358:j3448.

4. Wood NS, Marlow N, Costeloe K, Gibson AT, Wilkinson AR. Neurologic and developmental disability after extremely preterm birth. EPICure Study Group. N Engl J Med 2000;343:378-84.

5. Vohr BR, Wright LL, Dusick AM, Mele L, Verter J, Steichen JJ, et al. Neurodevelopmental and functional outcomes of extremely low birth weight infants in the National Institute of Child Health and Human Development Neonatal Research Network, 1993-1994. Pediatrics 2000;105:1216-26.

6. Silveira RC, Procianoy RS. High plasma cytokine levels, white matter injury and neurodevelopment of high risk preterm infants: assessment at two years. Early Hum Dev 2011;87:433-7.

7. Schlapbach LJ, Ersch J, Adams M, Bernet V, Bucher HU, Latal B. Impact of chorioamnionitis and preeclampsia on neurodevelopmental outcome in preterm infants below 32 weeks gestational age. Acta Paediatr 2010;99:1504-9.

8. Moore T, Johnson S, Haider S, Hennessy E, Marlow N. Relationship between test scores using the second and third editions of the Bayley Scales in extremely preterm children. J Pediatr 2012;160:553-8.

9. Kwun Y, Park HW, Kim MJ, Lee BS, Kim EA. Validity of the ages and stages questionnaires in Korean compared to Bayley Scales of infant development-II for screening preterm infants at corrected age of 1824 months for neurodevelopmental delay. J Korean Med Sci 2015; 30:450-5.

10. Heo KH, Squires J, Lee SY, Lee JS. Korean ages and stages questionnaires/ a parent completed development screening tool. Seoul: Seoul Community Rehabilitation Center, 2006.

11. Yim CH, Kim GH, Eun BL. Usefulness of the Korean Developmental Screening Test for infants and children for the evaluation of developmental delay in Korean infants and children: a single-center study. Korean J Pediatr 2017;60:312-9.

12. Jobe AH, Bancalari E. Bronchopulmonary dysplasia. Am J Respir Crit Care Med 2001;163:1723-9.

13. Papile LA, Burstein J, Burstein R, Koffler H. Incidence and evolution of subependymal and intraventricular hemorrhage: a study of infants with birth weights less than 1,500 gm. J Pediatr 1978;92:529-34.

14. Bell MJ, Ternberg JL, Feigin RD, Keating JP, Marshall R, Barton L, et al. Neonatal necrotizing enterocolitis. Therapeutic decisions based upon clinical staging. Ann Surg 1978;187:1-7.

15. Martin RJ, Fanaroff AA, Walsh MC. Fanaroff and Martin's neonatalperinatal medicine. 10th ed. Philadelphia (PA): Elsevier Health Sciences, 2014.

16. International Committee for the Classification of Retinopathy of Prematurity. The International Classification of Retinopathy of Prematurity revisited. Arch Ophthalmol 2005;123:991-9.

17. Pascal A, Govaert P, Oostra A, Naulaers G, Ortibus E, Van den Broeck C. Neurodevelopmental outcome in very preterm and very-lowbirthweight infants born over the past decade: a meta-analytic review. Dev Med Child Neurol 2018;60:342-55.

18. Colvin M, McGuire W, Fowlie PW. Neurodevelopmental outcomes after preterm birth. BMJ 2004;329:1390-3.

19. Moster D, Lie RT, Markestad T. Long-term medical and social consequences of preterm birth. N Engl J Med 2008;359:262-73.

20. Limperopoulos C, Bassan H, Sullivan NR, Soul JS, Robertson RL Jr, 
Moore M, et al. Positive screening for autism in ex-preterm infants: prevalence and risk factors. Pediatrics 2008;121:758-65.

21. Anderson PJ, De Luca CR, Hutchinson E, Roberts G, Doyle LW; Victorian Infant Collaborative Group. Underestimation of developmental delay by the new Bayley-III Scale. Arch Pediatr Adolesc Med 2010; 164:352-6.

22. Aylward GP. Developmental screening and assessment: what are we thinking? J Dev Behav Pediatr 2009;30:169-73.

23. Bayley N. Bayley scales of infant and toddler development. San Antonio (TX): The Psychological Corporation, 2006.

24. Doyle LW; Victorian Infant Collaborative Study Group. Evaluation of neonatal intensive care for extremely low birth weight infants in Victoria over two decades: I. Effectiveness. Pediatrics 2004;113(3 Pt 1):505-9.

25. Wood NS, Costeloe K, Gibson AT, Hennessy EM, Marlow N, Wilkinson AR, et al. The EPICure study: associations and antecedents of neurological and developmental disability at 30 months of age following extremely preterm birth. Arch Dis Child Fetal Neonatal Ed 2005;90:F134-40.

26. Kiechl-Kohlendorfer U, Ralser E, Pupp Peglow U, Reiter G, Trawöger R. Adverse neurodevelopmental outcome in preterm infants: risk factor profiles for different gestational ages. Acta Paediatr 2009;98:792-6.

27. Luttikhuizen dos Santos ES, de Kieviet JF, Königs M, van Elburg RM, Oosterlaan J. Predictive value of the Bayley scales of infant development on development of very preterm/very low birth weight children: a meta-analysis. Early Hum Dev 2013;89:487-96.

28. Bricker D, Squires J, Mounts L. Ages and stages questionnaire: a parent-completed, child monitoring system. Baltimore (MD): Paul H. Brookes, 1995:156.

29. Suh CR, Sohn SY, Kim GH, Jung SK, Eun BL. Single-center experience of the Korean-Developmental Screening Test for infants and children. Korean J Pediatr 2016;59:483-9.

30. Ga HY, Kwon JY. A comparison of the Korean-ages and stages questionnaires and denver developmental delay screening test. Ann Rehabil Med 2011;35:369-74.

31. Jeong SU, Kim GC, Jeong HJ, Kim DK, Hong YR, Kim HD, et al. The Validity of the Bayley-III and DDST-II in preterm infants with neurodevelopmental impairment: a pilot study. Ann Rehabil Med 2017; 41:851-7.

32. Moon JS, Lee SY, Eun BL, Kim SW, Kim YK, Shin SM, et al. One-year evaluation of the national health screening program for infants and children in Korea. Korean J Pediatr 2010;53:307-13.

33. Eun BL, Chung HJ, Cho S, Kim JK, Shin SM, Lee JH, et al. The Appropriateness of the Items of Korean Ages and Stages Questionnaires (K-ASQ) Developmental Screening Test in Korean infants and children. J Korean Child Neurol Soc 2014;22:29-41.

34. Council on Children With Disabilities; Section on Developmental Behavioral Pediatrics; Bright Futures Steering Committee; Medical Home Initiatives for Children With Special Needs Project Advisory Committee. Identifying infants and young children with developmental disorders in the medical home: an algorithm for developmental surveillance and screening. Pediatrics 2006;118:405-20.

35. Glascoe FP. Screening for developmental and behavioral problems. Ment Retard Dev Disabil Res Rev 2005;11:173-9. 